Ophthalmologica 1939;97:375

\title{
Punkt- und ringförmige Hornhautdystrophie
}

\begin{tabular}{|l|l|}
\hline A.J. & Ballantyne \\
\hline
\end{tabular}

Glasgow

I have read Dr. Kraup $\widehat{\text { s }}$ s communication with interest.

Let me assure him that I had no desire to reproach him because he was unaware of George Coats' paper. We all know the difficulty of tracing references, and I must admit that I was unaware of Kraupa's 1920 publication. But I felt that his suggestion that the white rings had not hitherto been noted, should not be allowed to pass without comment.

As regards the origin of the condition in question: the case quoted by Kraupa in which the opacity was found after removal of a calcareous foreign body from the cornea, points clearly to a traumatic origin; but we are still far from proving that this kind of injury is the source of the white rings in every case, indeed I find at least the first three of Kraupa's reasons in favour of a foreign body injury, much less convincing than the arguments which might be advanced against 